\title{
Research
}

\section{Trade-Offs in Values Assigned to Ecological Goods and Services Associated with Different Coral Reef Management Strategies}

\author{
$\underline{\text { Christina C. Hicks }}^{1,2}, \underline{\text { Tim R. McClanahan }}^{3}, \underline{\text { Joshua E. Cinner }}^{4}$, and $\underline{\text { Jeremy M. Hills }}^{5}$
}

\begin{abstract}
Societies value ecosystems and the services they provide in a number of ways. These values can help inform the management of ecosystems such as coral reefs. However, the trade-offs in ecosystem goods and services associated with different social and management conditions are poorly understood. Consequently, we examined values assigned to the goods and services identified across three types of management on the Kenyan coast: (1) a government-imposed no-take area in the Mombasa Marine National Park; (2) co-management of gear between fishing communities and the government's fisheries department; and (3) community-initiated no-take area management, where a community independently initiated and controlled a small closed area. We compared the ecosystem goods and services and the broader total economic value to explore how the history of these sites, their social conditions, and different management choices were associated with these values. The highest total economic values were associated with government management interventions and were probably due to the government's priority to be involved in the high-value beach tourism destinations. This is, however, associated with losses in a range of local community-level values and the social capital of the resource-user community. For example, resource users near the government marine protected area had the lowest value for measures of biological knowledge. Sites displaying greater community-level values were characterized by high social capital, and users had the most confidence in their ability to manage the resource. This study suggests that trade-offs occur in values associated with the interests and responsibilities of the management. The ability to cope with disturbance and change will depend on these values and responsibilities, and local communities are less likely to respond when government management and interests are strong.
\end{abstract}

Key Words: adaptive capacity; co-management; community-based management; ecological economics; fisheries closures; globalization; marine protected areas; social-ecological systems; total economic value

\section{INTRODUCTION}

The world is facing a natural resource crisis (Acheson 2006) precipitated by natural, climatic, and anthropogenic stressors that are predicted to increase in frequency and intensity (Hughes et al. 2007, Intergovernmental Panel on Climate Change (IPCC) 2007). A consequence of these pressures is a loss in the provision and value of the goods and services humans derive from natural ecosystems. These losses are often mediated by human motivation to manage for a few of the most profitable services, resulting in a loss in social, cultural, or ecological services. These trade-offs between less profitable cultural or ecosystem services and economic consumable services are likely to be nonlinear. For example, Barbier et al. (2008) found the economic value of shrimp production to peak at an intermediate level of mangrove conversion, suggesting it may be possible to maximize total economic value while minimizing ecological and cultural losses (Steffan-Dewenter et al. 2007, Hicks et al. 2008). As ecological functions and social features influence value, and they themselves are influenced by external features, correct identification of trade-offs is dependent on their incorporation into valuation studies. Social capital, for example, can alter whether or not a community is able to fully benefit from the goods and services present (Inkeles 2000). It is clear that to maintain the flow of goods and services, governance institutions need to integrate socioeconomic

\footnotetext{
${ }^{1}$ Newcastle University, ${ }^{2}$ ARC Centre of Excellence for Coral Reef Studies, James Cook University, ${ }^{3}$ Wildlife Conservation Society, ${ }^{4}$ Australian Research Council Centre for Excellence for Coral Reef Studies, ${ }^{5}$ ENVISION
} 
features with ecological processes to effectively manage biological resources (Ostrom 1990, Hughes et al. 2005, Wilson 2006, Ostrom 2007).

Social-ecological systems theory provides a useful perspective for linking social and ecological domains (Andersson et al. 2007) but has frequently lacked integration with ecological economics. Ecological economics combines ecology and economics to help explain the effects of, and motivations for, human action on ecosystems (Costanza et al. 1997, Armsworth and Roughgarden 2001). As such, ecological economics provides a valuable tool to quantify the trade-offs in ecosystem goods and services that societies frequently make in choosing how to manage or exploit resources (Barbier et al. 2008).

In this paper, we integrate ecological economics into a social-ecological systems perspective to quantify trade-offs in ecological goods and services associated with different social, ecological, and management conditions. As a case study, we use coral reef social-ecological systems in Kenya. Coral reefs provide crucial goods and services to some of the poorest, most densely populated, and growing human societies (Hughes et al. 2007), but are among the ecosystems most sensitive to disturbances (Bellwood et al. 2004). In response, various management measures have been developed to conserve and sustainably manage these ecosystems (McClanahan 2006). Comparison of social-ecological systems among such management scenarios provides an opportunity to assess trade-offs in ecosystem goods and services and the role social features play. We took advantage of three types of management systems associated with Kenyan coral reef fisheries to address the following research question: "How do differing management systems and social conditions contribute to differing values for ecological goods and services, and are trade-offs apparent?" To answer this question, we: (i) conducted a total economic valuation (TEV) of the coral reef fisheries associated with nine fish landing sites; (ii) identified the goods and services that were driving the economic values; (iii) examined relationships between eight key socioeconomic conditions and the ecosystem goods and services; and (iv) examined the detailed trends in sites and values in the absence of the dominant values.

\section{METHODS}

\section{Historical Context}

The East African coastline has had considerable research into the effectiveness of varying management advances on tropical fisheries (McClanahan and Mangi 2001, McClanahan 2007, Wells et al. 2007, McClanahan et al. 2008), sociocultural institutions governing resources (McClanahan et al. 1997), ecology (McClanahan et al. 2007), and perceptions of managers and resource users (McClanahan et al. 2005a). Kenyan fisheries are typical of the multi-gear, multi-species coral reef fisheries of many developing countries in the tropics, restricted by economic constraints. As a result, fishing is generally conducted from the shore to the outer reef in sand, coral, and seagrass habitats of the fringing reef lagoon (McClanahan and Mangi 2001).

Traditional conservation in Kenya is based on the belief that species and areas house spirits whose placation was crucial for the well being of society (McClanahan et al. 1997). A religious synchronism developed through the merging of the traditional animist spiritual beliefs and Islamic beliefs ca. 1700 A.D., resulting in the offering of sacrifices to appease the spirits (sadaka) (Glaesel 2000). Cultural traditions also consisted of controls on time, area, gear, and access to the fisheries (McClanahan et al. 1997). However, the colonial and post-colonial era drives for economic development and reduced local ethnic authority resulted in an open-access approach to fisheries management that was supported by national government policies and institutions. Around the same time, the economic stimulus provided by the growing tourism industry led the national government to establish an area-based park management system independent of the fisheries laws and regulations (McClanahan et al. 2005b).

Differences in the views of resource use between local and national government cultures resulted in conflicts, reorganization of resource use, and the subsequent loss of local ethnic traditions and controls (McClanahan 2007). More recently, in recognizing that fisheries resources are limited and overexploited, the government has taken advantage of naturally occurring differences in gear use patterns and perceptions to legislate a number or gear restrictions (Kenya Gazette Notice No. 7565, McClanahan 2007). This history and the conflict 
between traditional management, government management, and management for tourism has produced a reorganization around the need for restrictions. Varying levels of success in management measures have resulted in different management structures of different ages in effect in different areas (McClanahan et al. 2008).

\section{Study Sites}

To test for effects of management structure on the economic value and social characteristics of communities, we examined nine fish landing sites, representative of the three prominent management systems along an approximately $150-\mathrm{km}$ stretch of the southern Kenyan coastline. These were:

1. National Marine Protected Area (government managed). The Mombasa Marine National Park has been successfully enforced since 1991 (McClanahan et al. 2005b). Conflicts arising over the loss of fishing grounds after the closure were resolved through discussions that resulted in park border and gear use changes (McClanahan and Mangi 2000). Three landing sites adjacent to the park boundaries $(<1 \mathrm{~km})$ were studied and included Kenyatta beach, Marina, and Mtwapa (Fig. 1).

2. Co-management of gear (co-managed). Here, fishers fiercely opposed government attempts by the park service to implement a marine reserve in the mid 1990s. However, through associations with the government fisheries department and local governance structures, existing cultural gear restrictions led to the establishment of gear management in 2002, banning the use of the destructive beach seine nets (McClanahan et al. 2008). One landing site, Mwanyaza, has successfully eliminated the use of beach seines (long nets with small meshes often introduced by foreigners (McClanahan et al. 1997)) for over 20 years, and this initiative spread to other sites including Mgwani in 1999 and Chale in 2001.

3. Community-based closure (community managed). Sites have taken advantage of information from long-running scientific monitoring programs, combining this with existing local knowledge, resulting in a successful, enforced, and community-controlled small serial closed area since 2004. This new initiative has attracted the support and funding of other regional non-governmental organizations (NGOs) in the area. Three landing sites, include Mwanamia, Kuruwitu, and Vipingo, were studied.

\section{Data Collection}

We randomly selected eight respondents, representative of the age range and gear use at each site, using non-probability sampling techniques, including convenience and snowball sampling (Henry 1990). This sample size, which represented between $12 \%$ and $40 \%$ of the fishers at each landing site, was determined by running an a priori power analysis on reported catch, bequest, and option value responses (Quinn and Keough 2002).

\section{Social Characteristics}

We examined eight social characteristics thought to influence the ability of communities to collectively organize and manage their resources. These were: the number of fishers, age, migration status, occupational multiplicity, involvement in community organizations, followed up with involvement in decision making (Cinner 2005), and the presence of traditional sadaka ceremonies (Appendix 1). Involvement in community organizations, involvement in decision making, and the presence of traditional sadaka ceremonies are thought to characterize connectedness, relationships of trust, and rules and norms, all indicators of social capital (Pretty and Smith 2004). We established these characteristics using individual fisher surveys conducted at landing sites.

We calculated five indicators of resource exploitation: catch per unit effort (CPUE), gear dominance, fish price, fishing pressure, and fishery dominance (Appendix 1). The CPUE was established as the average catch in kilograms per fisher per day, gathered from one year's worth (2005) of a long-term fisheries statistics project (McClanahan et al. 2008). The total number of fishers and the number using each gear type were established from the same set of fisheries statistics (McClanahan et al. 2008) and checked against fisher 
Fig. 1. Map of the southern Kenyan coastline showing the nine study sites. Community (black triangle), Government (dark-gray square), Co- (light-gray circle).

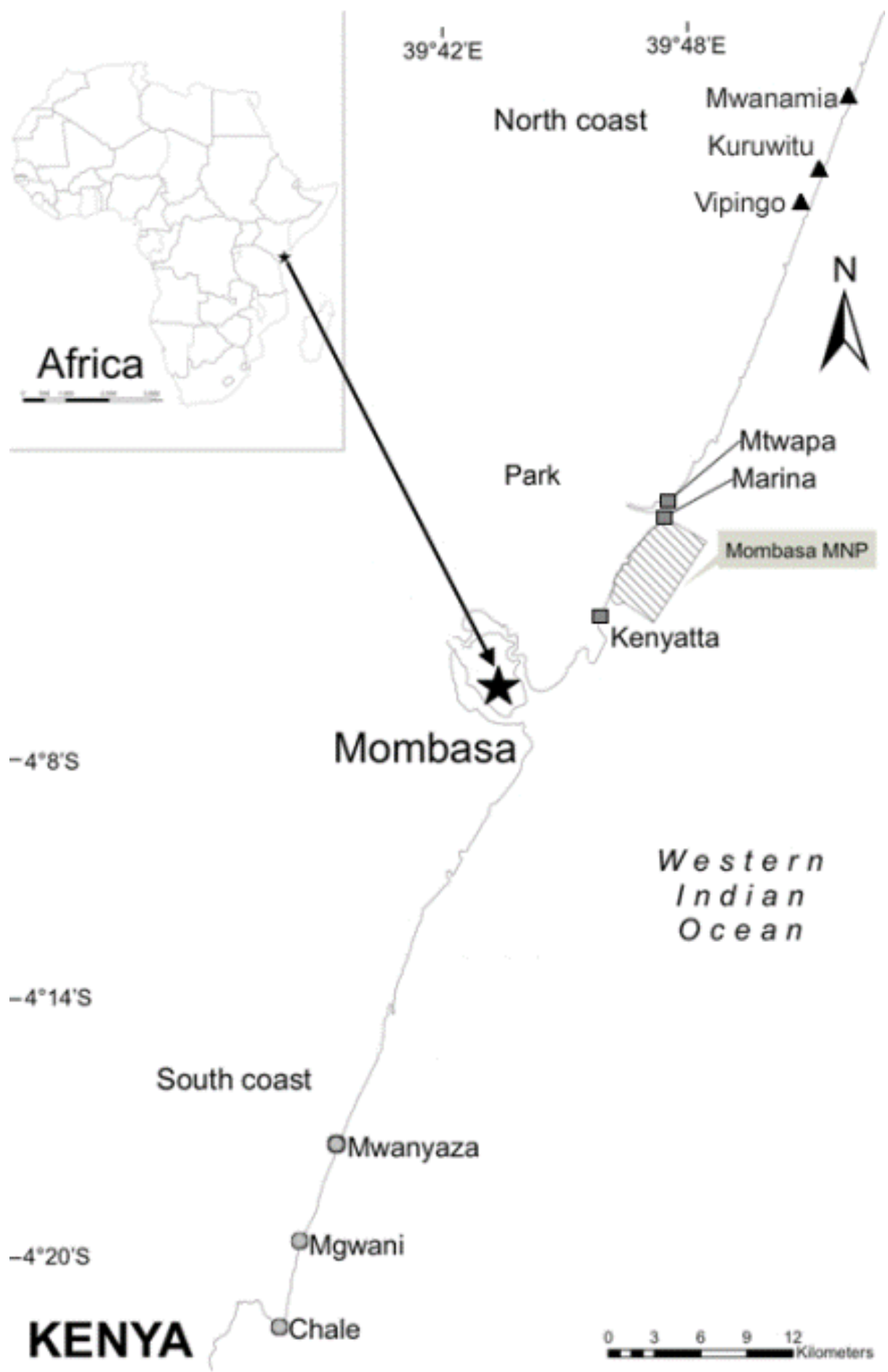


surveys and previous knowledge of all sites. A gear dominance index was calculated from these figures using Simpson's dominance index (Appendix 1). Fish prices were established during piloting and checked with fisher surveys. We calculated fishing pressure thus: (1) We calculated fishing areas by incorporating previous studies involving discussions with fishers (McClanahan and Mangi 2001, Cinner and McClanahan 2007) with satellite imagery, GPS positions, and spatial calculation functions in ArcGIS 9 (ESRI Inc., Redlands, California, USA) (McClanahan et al. 2008). (2) We divided the average daily fisher number by the area of fishing ground available to come up with a fishing effort per hectare of fishing ground. Fishery dominance is an index used to describe the extent to which areas of the fishery are exploited. We established which fisheries the respondents targeted from fisher surveys. The fisheries that represented catch composition and habitat were lagoon demersal, back reef demersal, back reef pelagic, octopus and shells, sea cucumber, and lobster. A fishery dominance index is calculated representing the proportion of fishers targeting these groups using Simpson's dominance index (Appendix 1). All analyses were conducted at the site level within each treatment.

\section{Economic Valuations}

Conventional economic valuation studies focus on the economic importance of services with the more intrinsic aspects of value neglected. Certain values, including cultural value, which is associated with folklore, painting, and tradition, have an intrinsic value distinguishable from the economic importance of revitalized and commercialized cultural heritage (Holden 2004). There is an important distinction between these two forms of values and, although it is difficult to separate them, there is a need to incorporate both in economic assessments of value. We grouped our economic goods and services into three broad categories: (1) direct use, comprising fishery, cultural, research, aesthetic, and recreation values; (2) indirect use, comprising biological control, habitat/refuge, waste regulation, and coastal protection values; and (3) non-use values, comprising bequest, option, and existence values (Spurgeon 1992, Moberg and Folke 1999) to incorporate both the economic importance of services with the more intrinsic aspects of value. Goods and services were further classified based on the scale at which they were supplied (Hein et al. 2006). When the beneficiaries of the goods and services lived within the communities being studied, the values were termed community values and included fishery, cultural, biological control, habitat and refuge, option, existence, and bequest (Appendix 1). Where the individuals lived outside the local area, the values were termed macroeconomic values, and included research, aesthetic, and recreation (Appendix 1).

\section{Direct-Use Values}

We calculated a "recreation service" value with a zonal travel cost method (TCM) (Freeman 2003, Bateman et al. 2004) (Appendix 1) using visitor numbers to the areas. Visitor numbers by their country of origin were collected from the main hotels in the co-managed and government-managed areas for all of 2005. No hotels exist in the community-managed area, and athough a few guest homes do exist, the numbers of visitors recorded were insufficient to calculate a consumer surplus using the TCM. The co-managed and governmentmanaged visitor numbers were standardized by the country populations and countries' GDP in US dollars at the purchasing power parity (PPP) (Eq. 1).

$$
V^{*}=\frac{10000 \mathrm{~V}}{P \times G D P}
$$

$\mathrm{V}^{*}=$ number of visitors standardized, $\mathrm{P}=$ population of country of origin, $\mathrm{GDP}=$ gross domestic product of country of origin \$PPP.

Linear relationships exist between the standardized visitor numbers and the costs of travel (co-managed, $\mathrm{F}_{1,16}=20.4, P<0.05, r^{2}=0.58$; governmentmanaged, $\left.\mathrm{F}_{1,10} \mathrm{~F}=15.7, P<0.05, r^{2}=0.64\right)$. These relationships were then used to calculate a consumer surplus, which attempted to compensate for income, based on the travel cost method (Bateman et al. 2004, Freeman 2003). The calculated consumer surplus for each coastal region was divided equally by the fish landing sites in the regions then by fishing area available to each, returning a standardized annual recreation service value per hectare.

We calculated an "aesthetic service" value using a 
hedonic price method (HPM) (Appendix 1), where 47 sale and estimate values for plots of land across the nine sites were collected from the Ministry of Lands. As the price of beach plots was considerably higher than non-beach plots, the assumption was made that the demand for beach plots came from outside the local area and as such is independent of proximity to a major town. The method used assumes that land price indirectly reflects the value of the aesthetic characteristics of the site (Turner et al. 1994, Brouwer 2000).

We calculated a "research service" value from the annual research budgets obtained from NGOs working in the regions. Research spending by NGOs does not distinguish between landing sites but refers to projects along a stretch of coast line. Therefore, the annual budget assigned to each area (corresponding to three adjacent landing sites in each area) was split equally among the fish landing sites and divided by the fishing area available to each, returning a standardized annual research service value per hectare (Appendix 1).

We calculated a "fishery goods" value using the respondents' catch and an ex-vessel price. The respondents' average day's catch was calculated at the site-specific ex-vessel (or the price fishers get for their catch) value. Values were multiplied by the number of days fishing in a year to give an individual annual fishery value. The mean individual fishery value for a site was multiplied by the total number of fishers at that site and divided by the area available to fish, giving a standardized annual fishery value per hectare.

To obtain a "cultural" value, respondents were asked to assign a rank of one to five to existence, option, biological control, bequest, and culture, five for the most important and one the least. Existence, option, biological control, and bequest all received independent valuations, which were used to establish the value for culture. Culture was assigned the value midway between the values of the goods or services one above and one below culture in rank (Eq. 2). In three cases out of 72, culture was ranked fifth; in these instances, the value for culture was two times that of the fourth in rank (Eq. 3).

$$
x_{n}=\left(x_{n-1}\right)+\frac{\left(x_{n+1}\right)-\left(x_{n-1}\right)}{2}
$$

If culture $=\mathrm{x}_{5}$

$$
x_{s}=2 \times\left(x_{4}\right)
$$

$n=\operatorname{rank}$

\section{Indirect Values}

"Waste regulation" and "coastal protection services" values were obtained using a value transfer method. The values calculated by Costanza et al. (1997) were adjusted for inflation at a fixed rate for 2005 (Appendix 1). Costanza et al. (1997) calculated service values for all coral reefs as value per hectare. This meant our sites did not differ in these values, so although these services contributed to the total economic value they were removed from further analysis as they did not contribute to differences across sites. These values were not categorized as demand curves were not constructed.

"Habitat/refuge" and "biological control" values were calculated using a combination of value transfer method and a posed hypothetical scenario. The values established were based on the levels of awareness in the community of the functions these services provided. The respondents answer a hypothetical scenario translated to a function awareness index ranging between 0 and 1 . The mean awareness index for a site was scaled using the biological control and habitat/refuge services values calculated by Costanza et al. (1997) and adjusted for inflation using 2005 inflation rates. The mean biological control and habitat/nursery values for a site were multiplied by the total number of fishers at that site and divided by the area available to fish, giving standardized annual values per hectare. 


\section{Non-Use Values}

Non-use values can only be measured using a contingent valuation (CV) method (Turner et al. 1994) as a result the values are difficult to confirm. It is possible, however, to validate a $\mathrm{CV}$ methodology. We calculated a "fishery goods" value using $\mathrm{CV}$ as a second method. A CV willingness to accept compensation for foregoing fishing was used to establish a stated fishery value for each respondent. The individual CV fishery value was scaled up to a year and the relationship between the fishery value obtained from the market value and the contingent valuation were examined using Pearson's correlation analysis after testing the two variables for normality. The two methods were found to be significantly correlated (Pearson's correlation $r=0.43, P=0.004$ ), validating the contingent valuation technique to be used in further valuations.

"Option," "bequest," and "existence" values were calculated using contingent valuation methodologies (CVM) (Appendix 1, Fig. A2) with a discrete choice format to establish the respondents' stated welfare measures for these goods and services (Bateman et al. 2004).

An "option" value was established through a willingness to incur extra travel costs to relieve fishing pressure and ensure sustained fisheries productivity to maintain the option for continued use within the community. A "bequest" value was established from a willingness to forego fishing and receive training in a new industry in order to leave fishing entirely and preserve the existing fish stocks for future generations. The respondent's willingness to incur extra time and effort, or forego fishing, scaled up to a year, was converted to a monetary value using their average catch rate at the sitespecific market value. The average catch rate was established from their stated good, bad, and average days' catch, their corresponding hours fishing, and traps laid out and days spent fishing.

An "existence value" was established from a willingness to accept compensation for the destruction of the coral reef within their fishing grounds when continued fishing had been secured elsewhere. The mean individual option, bequest, and existence values for a site were multiplied by the total number of fishers at that site and divided by the area available to fish, giving standardized annual values per hectare. As a suitable vehicle for payment was not found for existence value, the result was that some respondents refused to value existence. Due to the inherent difficulties in valuing existence, there were difficulties in valuing it, and the figures were treated with caution. Consequently, existence is included in the TEV, but removed from further analysis because it was viewed as a potential source of error in examining differences across sites.

\section{Data Analysis}

To compare whether the total, direct, indirect, and non-use values differed between management structures, we calculated the site-level total economic, direct-use, indirect-use, and non-use values for each site. To test the data for normality, we conducted a Ryner-Joiner test, and for homogeneity of variances, a Levene's test; where necessary, our data were transformed. To test for differences between management structures, a oneway analysis of variance (ANOVA) test was used, followed by a post hoc Tukey's honest significant differences (HSD) test. Where normality could not be achieved, non-parametric Kruskal-Wallis tests were used.

We used a redundancy analysis (RDA) to examine how economic values were related to: (1) spatial variation of the study sites, and (2) socioeconomic variables. Economic values were assigned as predictors and the site characteristics the response variables (ter Braak 1995, Quinn and Keough 2002). This analytical technique was deemed appropriate as the assumption that a linear relationship exists between economic values (square-root transformed) and the socioeconomic site variables was met. Recreation, aesthetics, and research had, by at least an order of magnitude, higher values than the other aspects of the TEV and appeared to be driving the clustering associations of sites. Therefore, to determine interactions of the lower-value aspects of the TEV, a principle component analysis was run on the square-root transformed data (Clarke and Warwick 2000, Quinn and Keough 2002), with these three high values and associated social variables removed.

\section{RESULTS}

National Marine Protected Area sites (government managed) and co-management of gear sites (comanaged) had a TEV and direct-use value three 
orders of magnitude greater than community-based closure (community managed) sites $\left(\mathrm{H}_{2,71}=48.6, P\right.$ $<0.005, \mathrm{H}_{2,71}=45.8, P<0.005$, respectively) (Fig. $2 \mathrm{a}, \mathrm{b}$, Table 1). Non-use values, which were a factor of four smaller than the TEV were valued highest in the community-managed (ca. $\$ 1774 \mathrm{ha}^{-1} \mathrm{yr}^{-1}$ ) and lowest in the government-managed $\left(\$ 821 \mathrm{ha}^{-1} \mathrm{yr}^{-1}\right)$ $\left(\mathrm{F}_{2,71}=5.97, P<0.005\right)$ sites (Fig. 2d, Table 1). Indirect-use values were highest in co-managed sites and lowest in government-managed sites $\left(\mathrm{F}_{2,71}=3.01, \mathrm{P}=0.056\right)$ (Fig. 1c, Table 1).

The co-managed and government-managed sites were distinct from the community-managed sites, and Chale differed among the co-managed sites. High recreation and aesthetic values drove the comanaged and government-managed sites, and these sites were characterized by high CPUE, dominance of a specific fishery target, older fishers, and higher levels of migrant fishers (Fig. 3). Chale under comanagement does not group together spatially with the other co-managed sites. Although it is still distinct, it lies closer to the community-managed sites, is driven by high fishery values, and is characterized by greater fishing pressures and occupational multiplicity. The community-managed sites were driven by high option, bequest, cultural, biological control, research, and to a lesser extent habitat/refuge values. These sites were characterized by a high retention of religious rituals, involvement in decisions, low levels of migrant fishers, and low CPUE (Fig. 3). Although the macroeconomic values were driving the trends, Marina under government management reflects the dominant use of one gear; Mwanyaza and Mgwani under co-management maintained traditional religious rituals and high levels of the biological control and habitat/refuge values (Tables 1 and 2).

The macroeconomic values (recreation, aesthetics, and research) were responsible for the close clustering of sites by area (Figs. 2, 3). Recreation represented the majority of the TEV of the comanaged and government-managed sites $(99.7 \%$ and $99.3 \%$, respectively). Aesthetic value was greater in the co-managed and governmentmanaged sites but represented the largest contribution of the TEV in the community-managed sites $(49.3 \%)$, followed by research $(38.7 \%)$ (Table $1)$. With the dominant values removed, the remaining community-level values are still responsible for the differences across management areas, separating the community-managed sites and Chale of the co-managed from the rest of the co- managed and government-managed sites (Fig. 4.). Sites under community management and Chale were characterized by high cultural, option, and bequest values whereas co-managed and governmentmanaged sites had low community values (Fig. 4).

\section{DISCUSSION}

This study analyzed economic and intrinsic values to assess the trade-offs associated with management choices and relate these to the social conditions at each site. A trade-off between community and global-market values was most evident. Community values are composed of economic and intrinsic value aspects, which are associated with high levels of social capital. In contrast, global-market values are predominantly composed of economic value aspects and are associated with national-level management.

The greatest distinction was between sites that had some form of government intervention (either government managed and co-managed) and those that did not. The government-managed and comanaged sites had equally high TEVs, suggesting that tourism development can have an equally high value with or without a marine park. In addition, the sites with government management had the lowest levels of a wide range of community-level values, including biological control. Given that our study is a snapshot in time, it is difficult to ascertain causation, which would require a similar study through periods of change.

The high TEV in the government-managed and comanaged sites were associated with large recreation and aesthetic consumer surpluses. It is likely that where these substantial consumer surpluses exist, such as along the best beaches, associated economic developments have occurred, and this is expected to attract government involvement in management. In most cases, marine protected areas have been established after considerable pressure on the government from the tourism sector (Alidina 2005). However, both recreation and aesthetic values are derived from the global market and are dependent on foreign demand curves that can leave the economy vulnerable to outside influences. These markets are also associated with the detrimental effects of unregulated tourism expansions, leaving communities to cope with increasing pressures on waste and sanitation services, the dilution of 
Fig. 2. Differences in total, direct, indirect, and non-use values across the three management areas \pm SE.
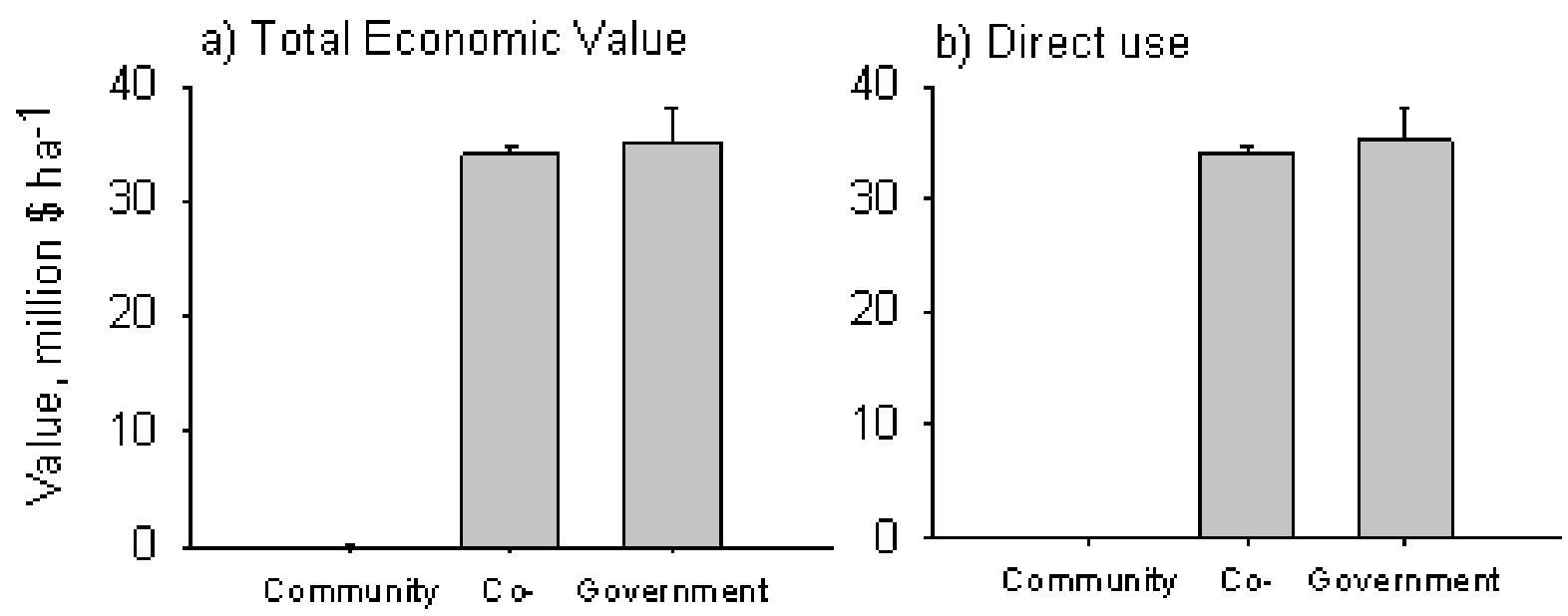

c) Indirect use

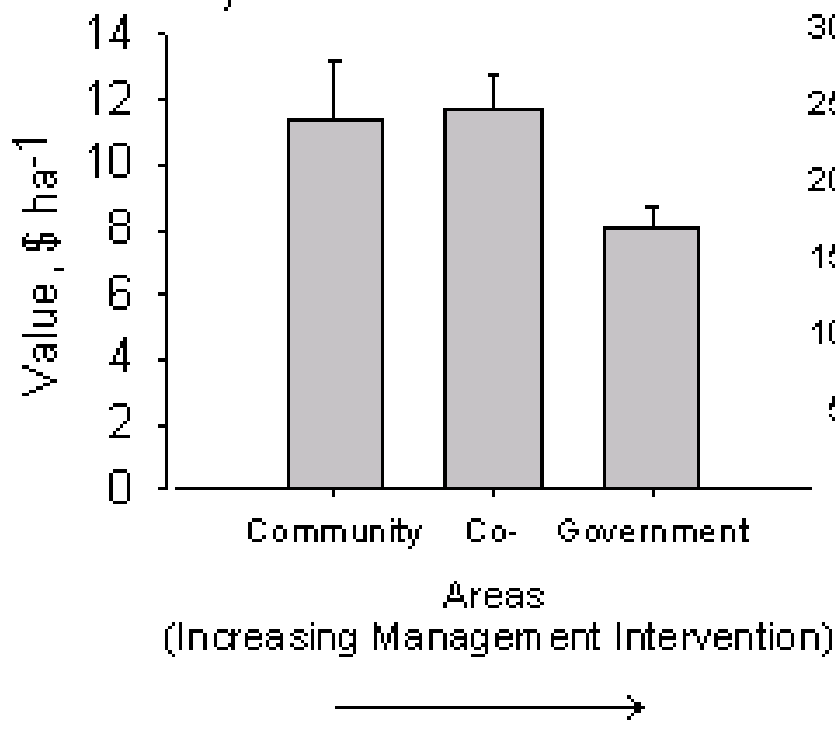

d) Non-use

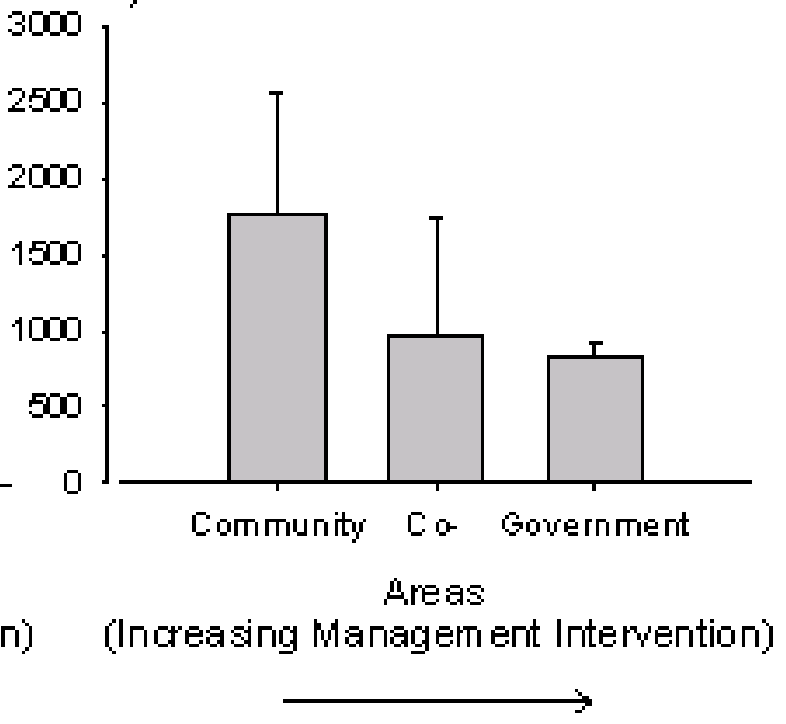

indigenous cultures, and the growth of prostitution and associated behavior (Brown et al. 1997).

The main drivers of the TEV in the communitymanaged sites are aesthetic and research values. Although these values are also likely to be driven by global markets, these sites also possess a wide range of indirect and non-use values that originate within the local communities (community values). In addition to high community values, these sites have maintained their traditional practices and have a larger proportion of their fishers considering themselves involved in decisions - both considered indicators of social capital (Pretty and Smith 2004). However, low CPUE values and low levels of migration may suggest a lack of confidence in the resources in these sites (Pollnac and Crawford 2000, Cinner 2005). The youngest fishers, who may be receiving family subsidies, come from these sites. This situation may have arisen because the beaches 
Table 1. Site-level goods and services mean values in $\$ \mathrm{ha}^{-1} \mathrm{yr}^{-1}$. Percent contribution for each good or service is shown aggregated at the management level. Numbers in bold indicate a good or service driving the total economic value in that management area.

\begin{tabular}{|c|c|c|c|c|c|c|c|c|c|c|c|c|c|}
\hline \multirow[b]{2}{*}{$\begin{array}{c}\text { Area } \\
\text { Value } \\
\left(\$ \mathrm{ha}^{-1}\right)\end{array}$} & \multirow[b]{2}{*}{ TEV } & \multirow[b]{2}{*}{$\begin{array}{l}\text { Fis- } \\
\text { hery }\end{array}$} & \multicolumn{3}{|c|}{ Direct use } & \multirow[b]{2}{*}{$\begin{array}{l}\text { Recre- } \\
\text { ation }\end{array}$} & \multicolumn{4}{|c|}{ Indirect use } & \multicolumn{3}{|c|}{ Non-use } \\
\hline & & & $\begin{array}{l}\text { Cult- } \\
\text { ural }\end{array}$ & $\begin{array}{l}\text { Resea- } \\
\text { rch }\end{array}$ & $\begin{array}{l}\text { Aest- } \\
\text { hetic }\end{array}$ & & $\begin{array}{l}\text { Biolo- } \\
\text { gical } \\
\text { control }\end{array}$ & $\begin{array}{l}\text { Habitat/ } \\
\text { refuge }\end{array}$ & $\begin{array}{l}\text { Waste } \\
\text { regula- } \\
\text { tion }\end{array}$ & $\begin{array}{l}\text { Coastal } \\
\text { protection }\end{array}$ & $\begin{array}{l}\text { Beq- } \\
\text { uest }\end{array}$ & $\begin{array}{l}\text { Opt- } \\
\text { ion }\end{array}$ & Existence \\
\hline \multicolumn{14}{|l|}{ Areas } \\
\hline $\mathrm{CBC}$ & 51845 & $0.6 \%$ & $0.4 \%$ & $38.7 \%$ & $49.3 \%$ & $0.0 \%$ & $0.0 \%$ & $0.0 \%$ & $0.2 \%$ & $7.5 \%$ & $0.4 \%$ & $0.6 \%$ & $2.5 \%$ \\
\hline $\mathrm{CMG}$ & $\begin{array}{r}34 \\
019 \\
311\end{array}$ & $0.0 \%$ & $0.0 \%$ & $0.0 \%$ & $0.2 \%$ & $\mathbf{9 9 . 7} \%$ & $0.0 \%$ & $0.0 \%$ & $0.0 \%$ & $0.0 \%$ & $0.0 \%$ & $0.0 \%$ & $0.0 \%$ \\
\hline NMPA & $\begin{array}{c}35144 \\
429\end{array}$ & $0.0 \%$ & $0.0 \%$ & $0.0 \%$ & $0.6 \%$ & $\mathbf{9 9 . 3} \%$ & $0.0 \%$ & $0.0 \%$ & $0.0 \%$ & $0.0 \%$ & $0.0 \%$ & $0.0 \%$ & $0.0 \%$ \\
\hline \multicolumn{14}{|l|}{ Site Value } \\
\hline $\begin{array}{l}\text { Mwanamia } \\
\text { CBC }\end{array}$ & 39854 & 308 & 304 & 21429 & $\begin{array}{c}13 \\
333\end{array}$ & 0 & 5 & 4 & 82 & 3866 & 236 & 269 & 19 \\
\hline $\begin{array}{l}\text { Kuruwitu } \\
\text { CBC }\end{array}$ & 56425 & 276 & 189 & 18750 & $\begin{array}{c}30 \\
000\end{array}$ & 0 & 4 & 7 & 82 & 3866 & 160 & 370 & 2722 \\
\hline $\begin{array}{l}\text { Vipingo } \\
\text { CBC }\end{array}$ & 59255 & 305 & 108 & 20000 & $\begin{array}{c}33 \\
333\end{array}$ & 0 & 6 & 9 & 82 & 3866 & 215 & 221 & 1111 \\
\hline $\begin{array}{l}\text { Mwanyanza } \\
\text { CMG }\end{array}$ & $\begin{array}{c}32871 \\
719\end{array}$ & 255 & 85 & 8658 & $\begin{array}{c}73 \\
966\end{array}$ & $\begin{array}{c}32784 \\
546\end{array}$ & 7 & 7 & 82 & 3866 & 138 & 111 & - \\
\hline $\begin{array}{l}\text { Mgwani } \\
\text { CMG }\end{array}$ & $\begin{array}{c}34585 \\
846\end{array}$ & 235 & 49 & 9112 & $\begin{array}{c}70 \\
148\end{array}$ & $\begin{array}{c}34502 \\
187\end{array}$ & 3 & 9 & 82 & 3866 & 83 & 73 & - \\
\hline $\begin{array}{l}\text { Chale } \\
\text { CMG }\end{array}$ & $\begin{array}{c}34600 \\
369\end{array}$ & 507 & 321 & 9112 & $\begin{array}{c}81 \\
783\end{array}$ & $\begin{array}{c}34502 \\
187\end{array}$ & 5 & 6 & 82 & 3866 & 286 & 427 & 1788 \\
\hline $\begin{array}{l}\text { Kenyatta } \\
\text { NMPA }\end{array}$ & $\begin{array}{c}29556 \\
763\end{array}$ & 159 & 41 & 13889 & $\begin{array}{l}293 \\
333\end{array}$ & $\begin{array}{c}29244 \\
694\end{array}$ & 4 & 4 & 82 & 3866 & 60 & 56 & 574 \\
\hline $\begin{array}{l}\text { Marina } \\
\text { NMPA }\end{array}$ & $\begin{array}{c}37938 \\
403\end{array}$ & 376 & 74 & 17921 & $\begin{array}{l}180 \\
000\end{array}$ & $\begin{array}{c}37735 \\
089\end{array}$ & 2 & 5 & 82 & 3866 & 109 & 122 & 758 \\
\hline $\begin{array}{l}\text { Mtwapa } \\
\text { NMPA }\end{array}$ & $\begin{array}{c}37938 \\
120\end{array}$ & 328 & 42 & 17921 & $\begin{array}{l}180 \\
000\end{array}$ & $\begin{array}{c}37735 \\
089\end{array}$ & 2 & 7 & 82 & 3866 & 159 & 151 & 473 \\
\hline
\end{tabular}


Fig. 3. Redundancy analysis (linear, direct gradient analysis) of the sites as driven by the economic valuation of the macro and community-level goods and services, with social variables overlain as eigenvectors. Economic values and socioeconomic variables were square-root transformed, and the ordination was value centered and standardized. The X-axis represents $48.4 \%$ and the $y$-axis $17.9 \%$ of the economic value-social variable variation. Community (black triangle), Government (dark-gray square), Co- (light-gray circle) economic values (black arrow), socioeconomic variable (gray lines).

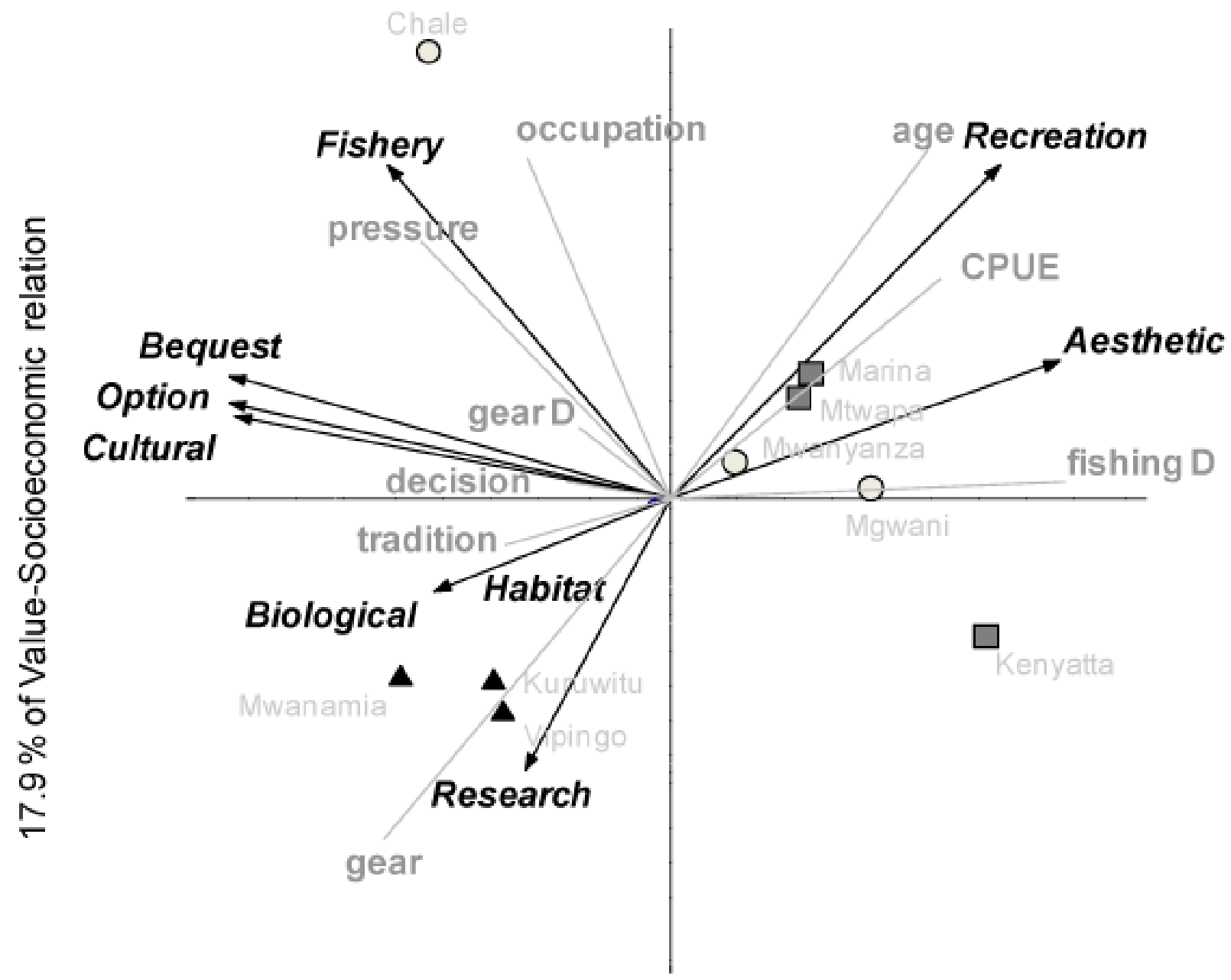


Table 2. Mean values for site-level socioeconomic characteristics. Age (years), involvement in decisions (ratio), tradition (ratio), migration (\% having migrated into the region), CPUE (kg fisher ${ }^{-1}$ day $^{-1}$ ), fishery dominance (Simpson's index), fishing pressure (fisher $\mathrm{km}^{-2}$ ), gear dominance (Simpson's index).

\begin{tabular}{lccccccccc}
\hline \hline & Age & Decisions & Tradition & $\begin{array}{c}\text { Number of } \\
\text { occupations }\end{array}$ & Migration & CPUE & $\begin{array}{c}\text { Fishery } \\
\text { dominance }\end{array}$ & $\begin{array}{c}\text { Fishing } \\
\text { pressure }\end{array}$ & $\begin{array}{c}\text { Gear } \\
\text { dominance }\end{array}$ \\
\hline Keruwitu & 34.8 & 0.75 & 0.88 & 2.0 & 0 & 1.2 & 0.21 & 22 & 0.47 \\
Mwanamia & 31.6 & 0.75 & 0.75 & 2.0 & 0 & 1.2 & 0.22 & 14 & 0.47 \\
Vipingo & 29.5 & 0.88 & 0.88 & 1.6 & 0 & 1.2 & 0.26 & 17 & 0.47 \\
Chale & 44.9 & 0.57 & 0.86 & 2.6 & 0 & 3.7 & 0.20 & 27 & 0.43 \\
Mwanyanza & 44.1 & 0.88 & 0.75 & 2.0 & 0 & 3.4 & 0.29 & 19 & 0.36 \\
Mgwani & 42.5 & 0.75 & 1.00 & 1.9 & 25 & 4.0 & 0.31 & 13 & 0.30 \\
Kenyatta & 41.2 & 0.22 & 0.67 & 1.8 & 63 & 4.1 & 0.28 & 9 & 0.23 \\
Marina & 39.4 & 1.00 & 0.50 & 1.8 & 50 & 1.3 & 0.32 & 24 & 0.91 \\
Mtwapa & 44.9 & 0.88 & 0.71 & 2.4 & 13 & 4.7 & 0.33 & 12 & 0.33 \\
\hline
\end{tabular}

in these sites do not provide the same potential for large-scale beach tourism and casual work that our government-managed and co-managed sites provide.

Option and bequest community-level values, also higher under community management, represent the willingness to pay to maintain the provision of ecosystem services, for themselves and others in the community now (option) and for future generations (bequest) (Spurgeon 2006). Consequently, where these values are high, it suggests that individuals are likely to value the sustained provision of ecosystem services at a community level. As ecosystem services represent common-pool resources, it is likely that a certain level of trust exists within the community that individuals do not act to maximize their individual benefit but in the best interest of the community as a whole (Ostrom 1990). The high levels of these values in the sites under community management as well as higher levels of our measured indicators of social capital (presence of traditional ceremonies, involvement in community organizations, and involvement in decisions), suggest lower transaction costs, creating a greater probability of coordinated actions that are needed for conservation efforts (Dietz et al. 2003). These sites do appear to be displaying such coordinated action, developing management practices in the face of low fishery yields. Whether this is a result of the high community values in these sites or the high community values are a result of community coordination is unclear, but they are associated with each other.

The lowest levels of community values, including biological control and habitat and refuge, exist in the government-managed sites. The biological control and habitat values are established from the respondents' levels of awareness of the functions that these services provide and their view of the importance. The assumption being that a community unaware of what constitutes a healthy functioning ecosystem will be unlikely to value it and unlikely to know what constitutes destructive behavior (Armsworth and Roughgarden 2001). It may be that economic development at these sites reduces these values to fishers and not government management, which is more likely responding to tourism development. However, the dependence on global markets reflects local-level vulnerability and a reliance on national and international institutions.

Management mechanisms available to avert overexploitation of a multi-species fishery include limiting the spatial extent of fishing and prohibiting 
Fig. 4. Pearson's correlation analysis (linear, indirect gradient analysis) of the sites showing only the community-level goods and services overlain as eigenvectors. PC1 represents $84.1 \%$ and PC2 represents $7.8 \%$ of the variation. Community (black triangle), Government (dark-gray square), Co- (light-gray circle), economic value (black line).

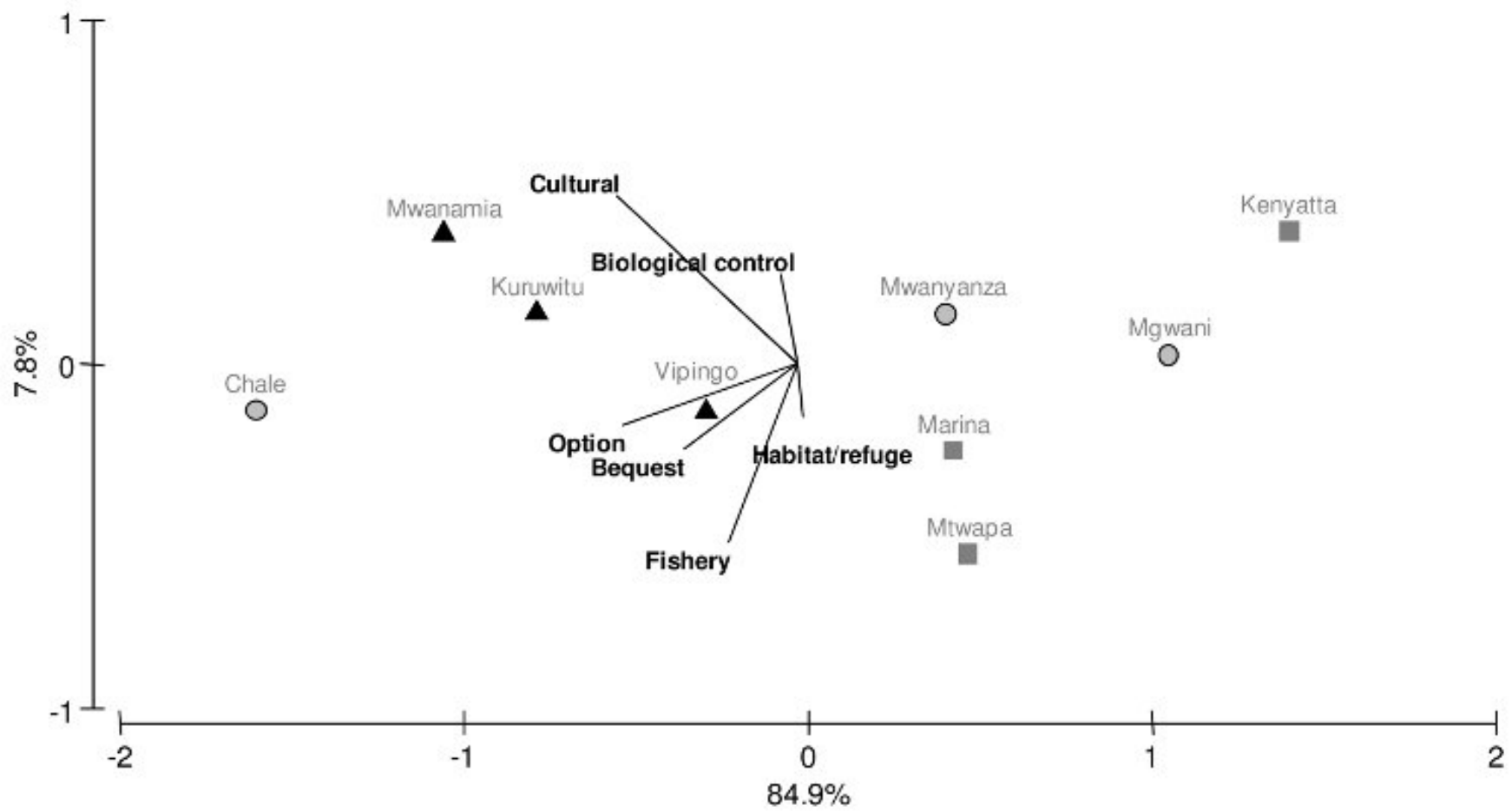

gears that are known to be destructive. The latter approach aims to maintain a mix of gears that do not overlap in their resource selectivity, such that selective pressure on key functional groups (e.g., predators of herbivores and sea urchins) is avoided (McClanahan and Mangi 2001). National controls on area and gear over the past 10 years have successfully reversed declining fishery yields in one site under government management (Kenyatta) and all sites under co-management, (McClanahan et al. 2008). However, one site under government management (Marina) with failed enforcement of national laws and a prevalence of destructive gear use, yielded some of the lowest CPUE values, despite its proximity to a marine park (McClanahan et al. 2008). The unsustainable resource use at this site is reflected in the low biological control values, representative of the government-managed sites, and consistent with expectations for low levels of social capital and confidence in management of the resource (Berkes and Turner 2006). In the absence of effective government management, compensation by local-level institutions is necessary to develop sustainable-use practices.

According to the depletion crisis model, conservation knowledge is developed as people discover their limits through exceeding them, which in turn develops new knowledge that may ultimately enable sustainable resource extraction or conservation (Berkes et al. 2000, Johannes 2002). Disturbance and change, therefore, provide opportunities for triggering new observations, learning, and the development of new socialecological feedbacks (Folke 2006). The low CPUE values of the community-managed sites, combined with high fishing pressures may be an example of this response. Within these sites, members of the community came together with the wealthier owners of beachfront properties to create an 
organization spanning a number of landing sites. This organization asked for advice from external conservation agencies on fisheries management options. The organization endeavored to combine different forms of knowledge: traditional, scientific, and business, in an attempt to develop a new form of sustainable and equitable resource management. A closed area was created partly in the hope of attracting tourism and to reverse resource depletion. In contrast, in the government-managed and comanaged sites, it was the external agencies that responded to the declining catch rates to negotiate area and gear management arrangements (McClanahan 2007).

Conventional economic valuations are routinely incorporated into management assessments. These approaches are amenable as they provide accepted methods that yield tangible and quantifiable results based on the value of the goods to the receiver. Goods and services containing intrinsic or donor value are more challenging to value and as a result are often undervalued, if valued at all (Odum 1996). Consequently, trade-offs should occur between consumable goods and services and intrinsic values, as the first is a recipient and the second a donor value. As perceptions change with education, advocacy, and culture, so too do the values a community holds for their ecosystem services (Costanza 2003). Such social conditioning would be expected to affect aspects of social capital, which in turn affect a community's ability to sustainably manage their natural resources (Ostrom 1990). Ecosystem services are vital to continued ecosystems functioning and as such are often referred to as supporting services (Hein et al. 2006). We have shown that intrinsic values are closely related to aspects of social capital, and together they constitute a vital social-ecological feedback mechanism that enables communities to collectively respond to resource changes. In the absence of government control, these values are expected to enable the sustainable use and conservation of natural resources. By integrating ecosystem service valuations with assessments of social capital, it should be possible to manage for a larger range of ecosystem services rather than maximizing a few with the highest recipient value.

\section{CONCLUSION}

Top-down management for specific ecosystem services can be effective in conserving biodiversity and increasing yields. However, trade-offs manifested in increases in more economically desirable services and decreases in less tangible intrinsic values may increase the vulnerability of social-ecological systems. This vulnerability is associated with a lower likelihood of developing mechanisms, for example through a depletion crisis model scenario, to learn and recover from disturbances such as environmental shocks and fluctuations in global markets. The consequences of these trade-offs may not be apparent until management fails or the system reaches an irreversible threshold. If the values necessary to coordinate action are lacking and there is inability to facilitate learning, the system may fail to recover. A wide range of ecosystem services and values are more likely to enable resilient and sustainable systems (Elmqvist et al. 2003).

Responses to this article can be read online at: http://www.ecologyandsociety.org/voll4/iss 1/art10/ responses/

\section{Acknowledgments:}

Support for this research was provided by the University of Newcastle and the Wildlife Conservation Society's Coral Reef Conservation Project; Kenya's Office of the President provided research clearance. We thank Carol Abunge and Rodgers for field assistance, Nick Graham for comments on earlier versions, and Ivan Weir for understanding economic evaluation.

\section{LITERATURE CITED}

Acheson, J. M. 2006. Institutional failure in resource management. Annual Review of Anthropology 35:117-134.

Alidina, H. M. 2005. Local level fisheries management in Diani-Chale, Kenya: current status and future directions. Coastal Management 33:459-470. 
Andersson, E., S. Barthel, and K. Ahrne. 2007. Measuring social-ecological dynamics behind the generation of ecosystem services. Ecological Applications 17:1267-1278.

Armsworth, P. R., and J. Roughgarden. 2001. An invitation to ecological economics. Trends in Ecology and Evolution 16:229-234.

Barbier, E. B., E. W. Koch, B. R. Silliman, S. D. Hacker, E. Wolanski, J. Primavera, E. F. Granek, S. Polansky, S. Aswani, L. A. Cramer, D. M. Stoms, C. J. Kennedy, D. Bael, C. V. Kappel, M. E. Perillo, and D. J. Reed. 2008. Coastal ecosystem-based management with non-linear ecological functions and values. Science 319:321323.

Bateman, I., A. A. Lovett, and J. S. Brainard, editors. 2004. Applied environmental economics: a GIS approach to cost benefit analysis. Cambridge University Press, Cambridge, UK.

Bellwood, D. R., T. P. Hughes, C. Folke, and M. Nyström. 2004. Confronting the coral reef crisisi. Nature 429:827-833.

Berkes, F., J. Colding, and C. Folke. 2000. Rediscovery of traditional ecological knowledge as adaptive management. Ecological Applications 10:1251-1262.

Berkes, F., and N. J. Turner. 2006. Knowledge, learning and the evolution of conservation practice for social-ecological system resilience. Human Ecology 34(4):479-494.

Brouwer, R. 2000. Environmental value transfer: state of the art and future prospects. Ecological Economics 32:137-152.

Brown, K., K. R. Turner, H. Hameed, and I. Bateman. 1997. Environmental carrying capacity and tourism development in the Maldives and Nepal. Environmental Conservation 24:316-325.

Cinner, J. E. 2005. Socioeconomic factors influencing customary marine tenure in the IndoPacific. Ecology and Society 10(1):36. [online] URL: http://www.ecologyandsociety.org/vol10/iss1/ $\underline{\operatorname{art} 36 / .}$.

Cinner, J. E., and T. R. McClanahan. 2007. A baseline socioeconomic assessment of fishing communities along the north coast of Kenya. Wildlife Conservation Societies Coral Reef Conservation Project, Final Report.

Clarke, K. R., and R. M. Warwick. 2000. Change in marine communities; an approach to statistical analysis and interpretation. Second edition. PRIMER-E Ltd., Plymouth, UK.

Costanza, R. 2003. A vision of the future of science: reintegrating the study of humans and the rest of nature. Futures 35(6):651-671.

Costanza, R., R. d'Arge, R. de Groot, S. Farber, M. Grasso, B. Hannon, K. Limburg, S. Naeem, V. O'Neill, J. Paruelo, R. G. Raskin, and P. Sutton. 1997. Value of the world's ecosystem services and natural capital. Nature 387:253-260.

Dietz, T., E. Ostrom, and P. C. Stern. 2003. The struggle to govern the commons. Science 302:19071912.

Elmqvist, T., C. Folke, M. Nyström, G. Peterson, J. Bengtsson, B. Walker, and J. Norberg. 2003. Response diversity, ecosystem change, and resilience. Frontiers 1:488-494.

Folke, C. 2006. Resiliance: the emergence of a perspective for socio-ecological systems analysis. Global Environmental Change 16:253-267.

Freeman, A. M. 2003. The measurement of environmental and resource values: theory and methods. Seccond edition. Resources for the Future, Washington, D.C., USA.

Glaesel, H. 2000. Community level marine resource management and the spirit realm in coastal Kenya. Women in Natural Resources 21:35-42.

Hein, L., K. van Koppen, R. S. de Groot, and E. van Ierland. 2006. Spatial scales, stakeholders and the valuation of ecosystem services. Ecological Economics 57:209-228.

Henry, G. T. 1990. Practical Sampling. SAGE Publications, Newbury Park, California, USA

Hicks, C. C., J. M. Hills, and M. LeTissier. 2008. Natural capital: valuing the coast. In D. R. Green, editor. Issues in coastal management. Telford Publishing, London, UK. (In press.) 
Holden, J. 2004. Capturing cultural value; how culture has become a tool of government policy. HenDI Systems, London, UK.

Hughes, T. P., D. R. Bellwood, C. Folke, R. S. Steneck, and J. Wilson. 2005. New paradigms for supporting resilience of marine ecosystems. Trends in Ecology and Evolution 20:380-386.

Hughes, T. P., L. H. Gunderson, C. Folke, A. H. Baird, D. Bellwood, F. Berkes, B. Crona, A. Helfgott, H. Leslie, J. Norberg, M. Nystrom, P. Olsson, R. S. Steneck, M. Tengoe, M. Troll, B. Walker, J. Wilson, and B. Worm. 2007. Adaptive management of the Great Barrier Reef and the Grand Canyon world heritage areas. Ambio 36:586592.

Inkeles, A. 2000 Measuring social capital and it's consequences. Policy Sciences33:245-268.

Intergovernmental Panel on Climate Change (IPCC). 2007 Climate change 2007: synthesis report. Contribution of Working Groups I, II, and III to the Fourth Assessment Report of the Intergovernmental Panel on Climate Change [Core Writing Team, R. K. Pachauri and A. Reisinger, editors). IPCC, Geneva, Switzerland.

Johannes, J. E. 2002. The renaissance of community-based marine resource management in Oceania. Annual Review of Ecology and Systematics 33:317-340.

McClanahan, T. R. 2006. Challenges and accomplishments towards sustainable reef fisheries. Pages 147-182 in I. M. Cote and J. D. Reynolds, editors. Coral reef conservation. Cambridge University Press, Zoological Society of London, Cambridge and London, UK.

McClanahan, T. R. 2007. Management of area and gear in Kenyan coral reefs. Pages 166-185 in T. R. McClanahan and J. C. Castilla, editors. Fisheries management: progress towards sustainability. Blackwell Press, London, UK.

McClanahan, T. R., J. Davies, and J. Maina. 2005a. Factors influencing resource users and managers' perceptions towards marine protected area management in Kenya. Environmental Conservation 32:42-49.

McClanahan, T. R., H. Glaesel, J. Rubens, and
R. Kiambo. 1997. The effects of traditional fisheries management on fisheries yields and the coral-reef ecosystems of southern Kenya. Environmental Conservation 24:105-120.

McClanahan, T. R., N. A. J. Graham, J. M. Calnan, and M. A. MacNeil. 2007. Towards pristine biomass: reef fish recovery in coral reef marine protected areas in Kenya. Ecological Applications 17:1055-1067.

McClanahan, T. R., C. C. Hicks, and E. S. Darling. 2008. Fishing pressure, productivity and competition for resources: Malthusian overexploitation and efforts to overcome it on Kenyan coral reefs. Ecological Applications 18:1516-1529.

McClanahan, T. R., and S. Mangi. 2000. Spillover of exploitable fishes from a marine park and its effect on the adjacent fishery. Ecological Applications 10:1792-1805.

McClanahan, T. R., and S. Mangi. 2001. The effect of a closed area and beach seine exclusion on coral reef fish catches. Fisheries Management and Ecology 8: 107-121.

McClanahan, T. R., S. Mwaguni, and N. A. Muthiga. 2005b. Management of the Kenyan coast. Ocean and Coastal Management 48:901-931.

Moberg, M., and C. Folke. 1999. Ecological goods and services of coral reef ecosystems. Ecological Economics 29:215-233.

Odum, H. T. 1996. Environmental accounting: emergy and environmental decision making. Wiley, New York, New York, USA.

Ostrom, E. 1990. Governing the commons: the evolution of institutions for collective action. Cambridge University Press, New York, New York, USA.

Ostrom, E. 2007. A diagnostic approach for going beyond panaceas. Proceedings of the National Academy of Sciences 104:15181-15187.

Pollnac, R. B., and B. R. Crawford. 2000. Assessing behavioral aspects of coastal resource use. Coastal Resources Center, University of Rhode Island, Narragansett, Rhode Island, USA.

Pretty, J., and D. Smith. 2004 Social capital in 
biodiversity conservation. Conservation Biology 18:631-638.

Quinn, G. P., and M. J. Keough, editors. 2002. Experimental design and data analysis for biologists. Cambridge University Press, New York, New York, USA.

Spurgeon, J. P. C. 1992. The economic valuation of coral reefs. Marine Pollution Bulletin 24:529536.

Spurgeon, J.P. C. 2006. Time for a third generation economics based approach to coral management. Pages 362-391 in I. M. Cote and J.D. Reynolds, editors. Coral reef conservation. Cambridge University Press, Zoological Society of London, Cambridge and London, UK.

Steffan-Dewenter, I., M. Kessler, J. Barkmann, M. M. Bos, D. Buchori, S. Erasmi, H. Faust, G. Gerhold, K. Glenk, S. R. Gradstein, E. Guhardja, M. Harteveld, D. Hertel, P. Hohn, M. Kappas, S. Kohler, C. Leuschner, M. Maertens, R. Marggraf, S. Migge-Kleian, J. Mogea, R. Pitopang, M. Schaefer, S. Schwarze, S. G. Sporn, A. Steingrebe, S. S. Tjitrosoedirdjo, S. Tjitrosoemito, A. Twele, R. Weber, L. Woltmann, M. Zeller, and T. Tscharntke. 2007. Trade-offs between income, biodiversity, and ecosystem functioning during tropical rainforest conversion and agroforestry intensification Proceedings of the National Academy of Sciences 104:4973-4978.

ter Braak, C. J. F. 1995. Ordination. Pages 91-173 in R. H. G. Jongman, C. J. F. ter Braak, and O. F. $\mathrm{R}$. van Tongeren, editors. Data analysis in community and landscape ecology. Cambridge University Press, Cambridge, UK.

Turner, R. K., D. Pearce, and I. Bateman, editors. 1994 Environmental economics: an elementary introduction. Harvester Wheatsheaf Publishing, New York, New York, USA.

Wells, S., M. Samoilys, J.Anderson, H. Kalombo, and S. Makoloweka. 2007. Collaborative fisheries management in Tanga, Northern Tanzania. Pages 139-165 in T. R. McClanahan and J. C. Castilla, editors. Fisheries management: progress towards sustainability. Blackwell Scientific, London, UK.

Wilson, J. A. 2006. Matching social and ecological systems in complex ocean fisheries. Ecology and
Society 11(1): 9. [online] URL: http://www.ecology andsociety.org/vol11/iss1/art9/. 
Appendix 1. Social and economic characteristics measured in the study; data sources, equations and methodologies used with economic level category based on consumer origin.

Please click here to download file 'appendix1.pdf'. 